\title{
Türki Cumhuriyetlerinde D1ş Borç Sürdürülebilirlik Analizi: Doğrusal Olmayan Panel Birim Kök Testi
}

\section{Gökhan KONAT ${ }^{1}$}

\section{Öz}

Ülke bazında dış borçlar artmaya başladığında politika yapıcılar kısıtlayıcı mali politikalar izlemektedir. Dış borçla mücadele politikaları için daha fazla kanıt sağlamak adına, dış borçların sürdürülebilirliği konusu literatürde dikkat çeken konulardan birisidir. Bu amaçla 1996-2019 dönemini kapsayan yıllık verilerle Türki Cumhuriyetlerde dış borcun sürdürülebilir olup olmadığı araştırılmak istenmektedir. Bunun için Dünya Bankası resmi veri tabanından elde edilen veri seti doğrusal olmayan panel birim kök analizi ile sınanmıştır. Elde edilen bulgulara göre serinin durağan olduğu görülmektedir. Bu ampirik sonuçlara göre Türki Cumhuriyetleri içeren ülke grubu için dış borcun sürdürülebilir olduğu sonucuna varılmaktadır.

Anahtar Kelimeler: D1ş Borç, Sürdürülebilirlik, Türki Cumhuriyetleri, Doğrusal Olmayan Panel Birim Kök

\section{External Debt Sustainability Analysis in Turkic Republics: Nonlinear Panel Unit Root}

Test

\section{Abstract}

Policy makers follow restrictive fiscal policies when country-based external debts begin to increase. In order to provide further evidence for policies to combat external debt, the issue of external debt sustainability is one of the highlights in the literature. For this purpose, it is aimed to investigate whether the external debt is sustainable in the Turkic Republics with annual data covering the 1996-2019 periods. For this, the data set obtained from the World Bank official database was tested by nonlinear panel unit root analysis. According to the findings, it is seen that the series is stationary. According to these empirical results, it is concluded that the external debt is sustainable for the country group including the Turkic Republics.

Key Words: External Debt, Sustainability, Turkic Republics, Nonlinear Panel Unit Root

\section{Atıf İçin / Please Cite As:}

Konat, G. (2021). Türki Cumhuriyetlerinde Dış Borç Sürdürülebilirlik Analizi: Doğrusal Olmayan Panel Birim Kök Testi. Manas Sosyal Arastırmalar Dergisi, 10(3), 1725-1734.

Geliş Tarihi / Received Date: 20.01.2021

Kabul Tarihi / Accepted Date: 03.06.2021

\footnotetext{
${ }^{1}$ Arş. Gör. Dr. Abant İzzet Baysal Üniversitesi, İ̈BF, Ekonometri Bölümü, Bolu, Türkiye, gokhan.konat@inonu.edu.tr,

iD ORCID: 0000-0002-0964-7893
} 


\section{Giriş}

Dış borç sürdürülebilirliğinin rolü, mali politikalar açısından son derece önemlidir. Artan hükümet açıkları ve borç seviyeleri hükümetler ve politika yapıcılar için hayati önem taşımaktadır. Dolayısıyla ülkelerin dış borç yükü, ekonomik ve sosyal ilerlemenin önündeki en önemli engellerden biri olarak görülmektedir. Bu nedenle dış borç sürdürülebilirliği, bir ülke ekonomisinin finansal istikrarının analiz edilmesinde kilit unsurlardan biridir. Özellikle gelișmekte olan ülkeler için sürdürülebilirlik en önemli araştırma alanlarından biri kabul edilmektedir. Büyük dış borç birikimi, devlet açığının yan ürünüdür. Daha yüksek dış borç, ülkenin ödeme gücü riskini arttırmaktadır. Bu durumla başa çıkmak için bir strateji olarak borç azaltma stratejileri üzerinde birçok çalışma geliştirilmektedir. Ağır Borçlu Yoksul Ülke (HIPC) Girişimi 1996 yılında başlatılmışır ve bu yoksul ülkelerin borçlarının hafifletilmesi IMF ve Dünya Bankası tarafindan denetlenmektedir (Lin, 2014, s. 31).

Dış borcun sürdürülebilirliği uzun zamandır ekonomi literatüründe bir çalışma konusu olmasına rağmen, bilim adamları bu konu için yeni analiz veya yöntem önermeye çalışmaktalar. Her ne kadar dış borçların sürdürülebilirliğine yönelik bir çok ampirik analiz bulunsa da bu çalışmanın temel amacı panel veri analizinde güncel testler ile konuya farklı bir bakış amacı geliştirmektir. Dış borç sürdürülebilirliğinin sağlanması için dış ticaret ve finansla ilgili beklenen döviz akışlarının belirli bir zamanda dengelenmesi ve bu zamanda ortaya çıkabilecek döviz akış uyumsuzluklarının uluslararası sermaye piyasaları tarafindan finanse edilmesi koşullarının gerçekleşmesi gerekmektedir (Pradelli, 2006, s. 5). Bu koşullar ödeme gücü ve likidite kavramlarıyla ilgili olduğu görülmektedir. Burada, ödeme gücü, likidite ve kırrlganlığın, borç sürdürülebilirliğinin içerdiği alt bileşenler olduğuna dikkat etmek önemli olmaktadır. Ödeme gücü, hükümetin faiz dışı fazlasının mevcut iskonto edilmiş değerinin, borç servisinin mevcut iskonto edilmiş değerinden daha büyük olduğu bir durum olarak tanınmaktadır. Öte yandan likidite, likit varlıkların ve mevcut özel finansmanın vadesi gelen yükümlülüklerini devretmeye yeterli olduğu, kırılganlık ise likiditenin bir ekonomik şokla kesintiye uğrama riski olarak ifade edilmektedir (Kıran, 2012, s. 18).

Sürdürülebilirliğin tanımlanmasında bazı güçlükler olmakta ve sürdürülebilirliğin koşulları konusunda iktisatçılar arasında fikir birliği olmadığı belirtilmektedir (Göktaş ve Hepsăg, 2015, s. 2). Diş borç sürdürülebilirliği için birçok tanım kullanılmaktadır. Mohammadi vd. (2007, s. 2442), bir ülkenin net gelecekteki net yabancı kazancının bugünkü değeri, dış borcunun bugünkü değerine eşitse, dış borcu sürdürülebilir olarak kabul ederken, Yılancı ve Özcan (2008, s. 92), bir ülkenin dış borç yükümlülüklerini yerine getirme kabiliyeti olarak ifade etmektedirler. IMF (2002), ise dış borç sürdürülebilirliğini bir borçlunun gelir ve gider dengesinde gerçekçi olmayan büyük bir gelecek düzeltmesi olmadan borçlarını ödemeye devam edebilmesinin beklendiği bir durum olarak tanımlanmaktadır. Ülke ekonomilerinde artış gösteren dış borç stoku, üretim ve ihracat gelirlerinin azaltmasına neden olmaktadır. Bunun haricinde dış borç stoku risk primini yükseltmekte ve sermaye girdisinde azalışa, çıktısında ise artışa sebep olmaktadır. Ayrıca dış borç stoku ülkelerin kredi notlarını düşürdüğü için devletlerin vergi taleplerini arttırmakta ve bu sebeple yatırımların azalmasına sebep olmaktadır (Yalçınkaya, 2019, s. 28).

Trehan ve Walsh $(1988,1991)$, dış borcun sürdürülebilirlik koşulunu aşağıdaki gibi tanımlamaktadır:

$$
S_{t}-S_{t-1}=\delta+\Psi(L) \epsilon_{t}
$$

Burada $S_{t}$ ve $S_{t}-S_{t-1}$ cari hesabı göstermektedir. Eğer cari hesap durağan ise hareketli ortalama süreci (1) nolu denklemdeki gibi yazılmaktadır. Burada $\epsilon_{t}$ beyaz gürültü sürecini $\delta$ ise bir sabiti göstermektedir. $L$ gecikme operatörü olup $\Psi(L)=\Psi_{0}+\Psi_{1} L+\Psi_{2} L^{2}+\cdots$ şeklindedir. (1) nolu eşitlik aşağıdaki gibi yeniden düzenlenebilir:

$$
\begin{aligned}
& S_{t+j}=\delta(j+1)+\Psi_{1}\left(\epsilon_{1}+\epsilon_{2}+\cdots+\epsilon_{t+j}\right)+\eta_{t+j}+\left(S_{t-1}-\eta_{t-1}\right) \\
& \text { Burada } \eta_{t}=\alpha(L) \epsilon_{t}=\sum_{j=0}^{\infty} \alpha_{j} L^{j} \epsilon_{t}, \alpha_{j}=-\left(\Psi_{j+1}+\Psi_{j+2}+\cdots\right)^{\prime} \text { dir. }
\end{aligned}
$$

Dış borcun sürdürülebilirliği için yeter koşul, gelecekteki borcun bugünkü değerinin sıfıra yaklaşması olarak ifade edilmektedir. $S_{t}-S_{t-1}$ carî hesap durağansa ve (2) no'lu eşitlik geçerli olursa, beklenen gelecekteki borcun bugünkü değerinin sıfıra yakınsadığı söylenebilmektedir. Çünkü gelecekteki beklenen borç doğrusal olarak büyürken, iskonto oranı $t \rho_{t+j}=\prod_{v=0}^{j} 1+r_{t+v}$ olarak katlanarak büyümektedir. Çünkü gelecekteki beklenen borç doğrusal olarak büyüdüğu ifade edilmektedir. Burada $r_{t+v}$ nominal faiz oranını göstermektedir. 


$$
\lim _{j \rightarrow \infty} E\left(t \rho_{t+j}{ }^{-1} S_{t+j} \mid I_{t-1}\right)=0
$$

Dış borcun durağan durumu genellikle borç-GSYIH oranı açısından analiz edilmektedir ve bu durumda, iskonto oranı $t \rho_{t+j}^{\prime}=\prod_{v=0}^{j}\left(\left(1+r_{t+v}\right) /\left(1+g_{t+v}\right)\right)$ olarak değiştirilmelidir. $g_{t+v}$ GSYİH büyüme oranını göstermektedir. $r_{t+v}>g_{t+v}$, yani ekonomi yeterli düzeyde etkiliyse, o zaman bahsedilen sürdürülebilirlik koşulu da geçerli olacağı belirtilmektedir (Takeuchi, 2010, s. 100).

Sawada (1994), açık bir ekonomide zamanlar arası bütçe kısıtlaması geliştirmiştir ve uluslararası borçlanma için ödeme gücü koșulunu türetmiştir. Koșul, herhangi bir sonlu net dış fazla dizisi için dıș borç-GSYİH oranının sınırlı kaldığını göstermektedir. Ampirik olarak, sürdürülebilirliğin belirlenmesi, durağan veya ortalama geri dönüşlü dış borcu tanımlamaya eşdeğerdir. Literatürde birim kök ya da eşbütünleşme testleri gibi tekniklerle sürdürülebilirlik konusu incelenmektedir (Nasir ve Noman, 2012, s. 673). Bu yöntemler ile bir hükümetin veya ülkenin dış borcunu ödemeksizin bütçesini veya dış açılarını devam ettirip ettiremeyeceği belirlenir (Önel ve Utkulu, 2006, s. 670). Bunun için diş borç sürdürülebilirliği de bazı oranlar veya göstergelerle ölçülmektedir. Örneğin, toplam dış borcun GSYİH'ye oranı önemli bir göstergedir. Borcun sürdürülebilirliğini sağlamak için, toplam dış borcun GSYIH'ye oranının sabitlenmesi gerekmektedir. Bu göstergeler/oranlar arasında en çok dikkate alınanlar Toplam Dış Borç Stoku/GSYIH; Toplam Dış Borç Stoku/İhracat; Toplam Dış Borç Servisi/İhracat; Toplam Dış Borç Faiz Servisi/İhracat; Toplam Dış Borç Faiz Servisi/GSYIH; Toplam Dış Borç Servisi/GSYIH; Toplam Dış Borç Servisi/Toplam Döviz Gelirleri; Uluslararası Rezervler/Toplam Dış Borç Stoku; Uluslararası Rezervler/İthalat; Kısa Vadeli Dış Borç/Toplam Dış Borç; Kısa Vadeli Dış Borç/Merkez Bankası Rezervleri; Cari İşlemler Dengesi/GSYİH; İhracat/İthalat; Reel Döviz Kuru Endeksi ve Büyüme Oranı şeklindedir (Çakmak, 2020, s.1843).

Bu ampirik çalısmanın amacı, açık bir ekonomide Türki Cumhuriyetleri (Kırgız Cumhuriyeti, Türkiye, Kazakistan, Özbekistan, Tacikistan, Türkmenistan) açısından dış borç sürdürülebilirliğini değerlendirmektir. Türki Cumhuriyetleri için son yıllarda ekonomik büyüme esas olarak tüketime ve inşaat hacmindeki artışa dayandığı için hassas bir konu olmaktadır. Nitekim Polat ve Fendoğlu (2021) y1lında yaptıkları çalışmada inşaat sektörünün Türkiye'nin son 20 yıllık dönemde yaşadığı ekonomik büyümenin en önemli dinamiklerinden birisi olduğu ve saatlik ücretlerdeki \%1'lik artışın saatlik üretimi en fazla inşaat sektöründe artırdığı sonucuna varmışlardır. 1996-2019 yılları arasında Türki Cumhuriyetleri’nin dış kısıtlamayı dış kısıtlamasını karşılayıp karşılamadığı araştırılmak istenmektedir. Serilerin yapılarına uygun testlerin kullanılması güvenilir sonuçlar elde edilmesi bakımından önem taşımaktadır. Bu nedenle gerçekleştirilen bu çalışmada doğrusal olmayan panel birim kök sınaması kullanılmıştır. Bunun için doğrusal olmayan panel birim kök sınaması gerçekleştirilmiştir. Bu test doğrusal olmayan sınamanın yanında yatay kesitsel bağımlılığı da dikkate almaktadır. Çalışmanın bir sonraki bölümünde kısa bir literatür değerlendirmesi yapılmaktadır. Ardından veri seti ve ekonometrik metodoloji yer almaktadır. Sonrasında bulgular gelmekte ve en son bölümde ise sonuç ve değerlendirme ile çalışma tamamlanmaktadır.

\section{Literatür}

Dış borç sürdürülebilirliği konusu, 1970'lerden beri teorik ve ampirik literatürde yaygin olarak tartışılmaktadır. Bazı düşük gelirli ülkeler için borç erteleme girişimleri ilk kez, alacaklıların istediği en düşük ortak paydadan ziyade, kısmen ülkelerin borçlarını sürdürülebilir kılma amacına dayandığından, bu konu 1996'dan beri çok daha önemli hale gelmiştir (Kıran, 2012, s. 18). Literatürde dış borç sürdürülebilirlik sınaması için çeşitli ülke ya da ülke grupları için yapılmış birçok araştırma mevcuttur. Sürdürülebilirlik konusunu sınamak için tercih edilen seçenekler birim kök (durağanlık) ve eşbütünleşme testleridir. Bu çalşmada birim kök analizi ile sürdürülebilirlik sınaması gerçekleştirildiği için, literatür taraması sadece birim kök sınaması üzerine olan çalışmalarda yapılmıştır. Literatür özeti Tablo 1'de sunulmaktadır. 
Tablo 1. Literatür Özeti

\begin{tabular}{|c|c|c|c|}
\hline Yazar(lar) & Dönem(ler) & Yöntem(ler) & Sonuç \\
\hline Hamilton ve Flavin (1986) & $1962-1984$ & Birim kök analizi & ABD için dış borçlar sürdürülebilirdir. \\
\hline Trehan ve Walsh (1991) & $1946-1987$ & Birim kök analizi & ABD için dış borçlar sürdürülebilir değildir. \\
\hline Buiter ve Patel (1992) & $1970 / 71-1986 / 87$ & Birim kök analizi & Hindistan için dış borçlar sürdürülebilirdir. \\
\hline Sawada (1994) & $1955-1990$ & Birim kök analizi & $\begin{array}{l}\text { Asya ülkeleri için, Filipinler hariç, diş } \\
\text { borçlar sürdürülebilir, Latin Amerika } \\
\text { ülkeleri için diş borçlar sürdürülebilir } \\
\text { değildir }\end{array}$ \\
\hline Caporale (1995) & $\begin{array}{l}\text { Bazı ülkeler için } 6 \\
\text { aylık, bazıları için } \\
\text { yıllık }\end{array}$ & Birim kök analizi & $\begin{array}{l}\text { Seçilen bazı Avrupa ülkeleri için dış borçlar } \\
\text { sürdürülebilir değildir }\end{array}$ \\
\hline Wu (2000) & 1977Q1-1997Q4 & IPS birim kök analizi & $\begin{array}{l}10 \text { OECD ülkesi için dış borçlar } \\
\text { sürdürülebilirdir. }\end{array}$ \\
\hline Lau ve Baharumshah (2005) & 1970-2002 & SURADF birim kök analizi & $\begin{array}{l}12 \text { Asya ülkesi için dış borçlar } \\
\text { sürdürülebilirdir. }\end{array}$ \\
\hline Yllanc1 ve Özcan (2008) & 1990:Q1-2007:Q2 & TAR model & $\begin{array}{l}\text { Türkiye için dış borçlar sürdürülebilir } \\
\text { değildir }\end{array}$ \\
\hline Takeuchi (2010) & 1961Q1-2008Q4 & Markov Zinciri birimi kök & $\begin{array}{l}\text { ABD için dış borç sürdürülebilirlik } \\
\text { olasılığının beklenmedik şekilde yüksektir }\end{array}$ \\
\hline Boengiu vd. (2011) & 1990Q4-2010Q4 & Kantil otoregresyon model & $\begin{array}{l}\text { Romanya için dış borçlar } \% 5 \text { düzeyinde } \\
\text { sürdürülebilir değildir }\end{array}$ \\
\hline Nasir ve Noman (2012) & $1973-2008$ & $\begin{array}{l}\text { Doğrusal olmayan birim kök } \\
\text { analizi }\end{array}$ & $\begin{array}{l}\text { Ülke grubu için dış borçlar sürdürülebilir } \\
\text { değildir. }\end{array}$ \\
\hline Kiran (2012) & $1970-2010$ & $\begin{array}{l}\text { Çoklu yapısal kırılmalı birim } \\
\text { kök analizi }\end{array}$ & $\begin{array}{l}\text { Türkiye için dış borç̧lar sürdürülebilir } \\
\text { değildir }\end{array}$ \\
\hline Lau vd. (2013) & $1981-2010$ & Panel birim kök testi & $\begin{array}{l}19 \text { Asya ülkesi için dış borçlar } \\
\text { sürdürülebilirdir }\end{array}$ \\
\hline Lin (2014) & 1980Q1-2013Q3 & Kantil otoregresyon model & $\begin{array}{l}21 \text { OECD ülkesinden } 6 \text { ülke için dış } \\
\text { borçlar sürdürülebilirdir }\end{array}$ \\
\hline Göktaş ve Hepsağ (2015) & 1990Q1-2012Q3 & $\begin{array}{l}\text { Yapısal kırılmalı birim kök } \\
\text { analizi }\end{array}$ & $\begin{array}{l}\text { Türkiye için dış borç̧lar sürdürülebilir } \\
\text { değildir }\end{array}$ \\
\hline Yalçınkaya (2019) & $1970-2018$ & $\begin{array}{l}\text { Doğrusal ve doğrusal olmayan } \\
\text { birim kök testi }\end{array}$ & $\begin{array}{l}\text { Türkiye için dış borçlar sürdürülebilir } \\
\text { değildir }\end{array}$ \\
\hline
\end{tabular}

\section{Veri Seti ve Yöntem}

Bu çalışmada 1996-2019 dönemini kapsayan yıllık veriler ile Türki Cumhuriyetler içerisinde yer alan Türkiye, Kırgizistan, Azerbaycan, Kazakistan, Özbekistan, Tacikistan ve Türkmenistan ekonomilerinde için dış borcun sürdürülebilir olup olmadığı araştırılmaktadır. Gözlemler Dünya Bankası resmi veri tabanından ulaşılmıştır. Seçilen ülke grubu için dış borcun sürdürülebilir yapı sergileyip sergilemediği doğrusal olmayan panel birim kök analizi ile gerçekleştirilmiştir. Öncesinde serilere yatay kesit bağımlllkk analizi yapılmış ve seriler yatay kesitsel olarak bağımlı bulunduğu için II. kuşak birim kök testi uygulanmıştır.

\section{SURKSS Birim Kök Testi}

Wu ve Lee (2009) tarafindan önerilen bu test, Görünürde İlişkisiz (SUR) denklemleri ile serilerin doğrusal olmayan bir yapı izlediği varsayımına dayanan model yapısı önermişlerdir. Bu modelde seriye özgü doğrusal olmayan panel birim kök testi ile serinin doğrusal olmayan ortalamaya dönmesi incelenmektedir. Veri üretme süreci önemli doğrusal olmayan davranışları yansıtacak şekilde oluşturulmuştur. Panel birim-kök testlerini seçmenin en büyük avantajı, yatay-kesitsel bilgileri kullanarak testin gücünün artması sağlanmaktadır. Var olan metotlar arasında literatürdeki tüm çalışmalar sıfır hipotezini reddetmenin bireysel serilerin durağanlığı için çok az bilgi sağlamaktadır ve kısttlamalar altında birleşik birim kök hipotezini test etmek için bir lineer yapıya uymaktadır. Doğrusal olmayan seriye özgü panel birim kök testi Breuer vd. (2001) tarafindan önerilen SURADF testinden daha güçlü olduğunu göstermişlerdir. $\mathrm{Bu}$ testte, SURADF panel birim kök testinde kullanılan ADF regresyonları yerine Kapetanios vd. (2003, KSS) tarafindan önerilen doğrusal olmayan regresyon kalıbı kullanılmaktadır. Ayrıca SURKSS birim kök testi serilerdeki yatay kesit bilgisini kullanmakta ve eşzamanlı korelasyon ile heterojen serisel korelasyonu da dikkate almaktadır. 
Veri yaratma süreci doğrusal olmadığında, lineer birim kök testlerini kullanmak yanlı sonuçlar verebilir. Bu nedenle, yatay kesit bilgisinden yararlanılarak paneldeki her bir seri için birim kök hipotezini test etmelerine izin veren spesifik lineer olmayan panel birim kök testi olan SURKSS modeli literatüre kazandırılmıştır. SURKSS birim kök testi, görünürde ilişkisiz regresyon (SUR) yöntemine dayanır ve eşzamanlı korelasyon ve heterojen serisel korelasyon ele alır. Model aşağıdaki gibi gösterilmektedir:

$$
\Delta y_{k, t}=\alpha_{k}+\beta_{k} y_{k, t-1}+\sum_{j=1}^{\rho_{k}} \phi_{k j} \Delta y_{k, t-j}+\varepsilon_{k, t}, t=1,2, \ldots, T \text { ve } k=1,2, \ldots, N
$$

Burada $\varepsilon_{k, t} 0$ ortalamalı durağan bir süreçtir (Wu ve Lee, 2009: s. 591-592).

Breuer vd. (2002), (4) eşitliğine göre sıfir ve alternatif hipotezi test etmek için SURAFDF ${ }^{k}$ istatistiklerini geliştirmişlerdir ve hipotezler aşağıda tanımlandığı gibidir:

$$
\begin{aligned}
& H_{0}^{k}: \beta_{k}=0 \\
& H_{1}^{k}: \beta_{k}<0
\end{aligned}
$$

Burada $k=1,2, \ldots, N$ 'dir. Bu hipotezler, SUR tahminlerinden oluşturulan t-istatistikler kullanılarak test edilmektedir ve simule edilmiş kritik değerlere sahiptir. $t$-istatistiklerinin kritik değerleri Monte-Carlo simülasyonlarından simüle edilir, çünkü t-istatistiklerinin SUR sisteminden sonlu örnek dağıllimı bilinmemektedir.

KSS birim kök yapısı aşağıdaki gibi ifade edilmektedir:

$$
\Delta y_{t}=\delta y_{t-1}^{3}+\sum_{j=1}^{p} \phi_{j} \Delta y_{t-j}+\varepsilon_{t}
$$

Eğer $\hat{\delta}<0$ 'a karşı $\hat{\delta}=0$ hipotezi reddediliyorsa o zaman $y$ serisinin doğrusal olmayan durağan bir seri olduğu iddia edilir. Burada $\hat{\delta}=0$ hipotezi için $t$ istatistiğinin asimptotik dağılımı Kapetanios vd. (2003) tarafından belirtildiği gibi standart değildir. Sifir olmayan ortalama ile bir stokastik sürece uyum sağlamak için, Kapetanios vd. (2003) tahminde ortalamadan farkı alınmış verilerin kullanılmasını önermektedir. Doğrusal olmayan bir modelde ortalamadan farkı alınmış verilerin kullanılması, bir sabitin alternatif hipotez altında modele girme şeklinin belirli bir görünümünü ifade eder. Eğer model sabit ve trend içeriyorsa, test istatistiği, ortalamadan farkı alınmış ve trendden arındırılmış verilerle tahmin edilerek aşağıdaki eşitlik oluşturulur. Kapetanios vd. (2003)'nin doğrusal olmayan birim kök testini panel çerçevesine genelleştirilmiş hali ve paneldeki her seri için durağanlık testine izin veren form aşağıdaki sistem denklemlerini göz önünde bulundurularak oluşturulmuştur:

$$
\Delta y_{k, t}=\delta_{k} y_{k, t-1}^{3}+\sum_{j=1}^{p_{k}} \eta_{k, j} \Delta y_{k, t-j}+\varepsilon_{k, t}, \quad k=1,2, \ldots, N
$$

(6) nolu eşitliği SUR ile tahmin edildikten sonra, $\hat{\delta}=0$ hipotezi için $t$-istatistiği daha sonra spesifik serilerin durağanlığını test etmek için oluşturulur (Wu ve Lee, 2009: s. 593).

\section{Bulgular}

Ülkeler adına dış borcun sürdürülebilirliği mali ve finansal açıdan son derece önemlidir. Bu amaçla bu konu birçok araştırmacı tarafindan (Croce ve Juan-Ramon, 2003; Mendoza ve Oviedo, 2004; Hauner vd., 2007; Ono, 2008; Göktan, 2008; Ucal ve Alıc1, 2010; Hepsağ, 2011; Çakmak, 2020) ilgi odağı olmuştur. 1996-2019 dönemini kapsayan yıllık serilere Dünya Bankası resmi veri tabanından ulaşılmıştır ve ABD doları cinsinden toplam dış borç üzerinden borç servisi verileri kullanılmıştır. Toplam borç servisi, uzun vadeli borçlar için para birimi, mal veya hizmet olarak ödenen anapara geri ödemeleri ve faizin, kısa vadeli borç için ödenen faizin ve IMF'ye yapılan geri ödemelerin (geri alımlar ve masraflar) toplamı olarak tanımlanmaktadır. Bu çalışmada dış borç sürdürülebilirlik sınaması Türki Cumhuriyetler için araştırılmıştır. Bunun için öncelikle elde edilen serinin yatay kesit bağımlllk sınaması gerçekleştirilmiş ve ardından durağanlık analizi yatay kesit bağımlılı̆g dikkate alan ve doğrusal olmayan panel birim kök yardımı ile gerçekleştirilmiştir. Sonuçlar aşağıdaki tablolarda sunulmuştur. 


\begin{tabular}{lccc}
\hline \multicolumn{1}{c}{ Test } & Ístatistik Değeri & Olasıllk Değeri \\
\hline Breusch-Pagan (1980) & 274.968 & $0.000^{* * *}$ \\
Pesaran (2004) CD LM & 39.188 & $0.000^{* * *}$ \\
Pesaran (2004) CD & 39.035 & $0.000^{* * *}$ \\
Sapması Düzeltilmiş Pesaran (2008) CD LM & 7.492 & $0.000^{* * *}$ \\
\hline Not: *** \%1 düzeyinde anlamlllı̆̆ ifade etmektedir. & & \\
\hline
\end{tabular}

Tablo 2'deki yatay kesit bağımlılık test sonuçlarına göre, yatay kesit bağımlılı̆̆ın olmadığını iddia eden sıfır hipotez reddedilir. Dolayısıyla seriye yatay kesit bağımlılı̆ını dikkate alan birim kök testi uygulanması gerektiğine karar verilir. Bu amaçla SURADF ve SURKSS birim kök sınaması gerçekleştirilmiştir. SURADF doğrusal formda olan ve yatay kesit bağımlllı̆̆ dikkate alan birim kök sürecine sahiptir. SURKSS birim kök testi yatay kesit bağımlılı̆ı dikkate almanın yanında doğrusal olmayan bir formdadır. Doğrusal olmayan tekniklerin hem durağan süreçleri belirlemede hem de sabit bir serinin ayarlama sürecini doğru bir şekilde tahmin etmede doğrusal tekniklere göre üstün performansa sahip olduğu literatürce kabul edilmektedir. Doğrusal ve doğrusal olmayan birim kök test sonuçları aşağıda Tablo 3'te ve Tablo 4'te sunulmaktadır.

Tablo 3. SURADF Birim Kök Test Sonuclar

\begin{tabular}{lcccc}
\hline \multicolumn{1}{c}{ Ülkeler } & Test Íst. & \%1 & \%5 & \%10 \\
\hline Türkiye & -3.990 & -6.767 & -5.375 & -4.799 \\
Kirgizistan & -2.764 & -7.694 & -6.614 & -6.114 \\
Azzerbaycan & -1.888 & -7.418 & -6.376 & -5.861 \\
Kazakistan & -1.849 & -7.576 & -6.649 & -6.031 \\
Özbekistan & -1.636 & -6.905 & -5.426 & -4.823 \\
Tacikistan & $-5.257 *$ & -7.044 & -5.504 & -4.978 \\
Türkmenistan & -2.502 & -7.187 & -5.461 & -4.949 \\
\hline
\end{tabular}

Not: * \%10 düzeyinde anlamlılı̆ı ifade etmektedir. Kritik değerler 10.000 Bootstrap ile elde edilmiştir.

Elde edilen doğrusal SURADF birim kök test sonuçlarına göre sadece Tacikistan'ın \%10 seviyesinde dış borcun sürdürülebilir olduğu, diğer ülkelerin ise diş borcunun sürdürülemez olduğu bulgusuna ulaşılmıştır. Bu durum Tacikistan haricindeki diğer ülkelerin orta/uzun vadede dış borç krizi sorunu ile karşılaşabileceklerini göstermektedir. Türkiye için yapılan çalışmalar incelendiğinde literatür ile uyumlu sonuçlar elde edildiği görülmektedir. Bu durum dış borcun sürdürülebilir seviyeye indirilebilmesi için tasarruf artırıcı tedbirler alınması ve dış borcun GSYİH'ye oranının düşürülmesi gerekmektedir.

Tablo 4. SURKSS Birim Kök Test Sonuclar

\begin{tabular}{lcccc}
\hline \multicolumn{1}{c}{ Ülkeler } & Test Íst. & \%1 & \%5 & \%10 \\
\hline Türkiye & $-13.865^{* * *}$ & -2.3793 & -1.6567 & -1.2462 \\
Kirg1zistan & $-9.765^{* * *}$ & -2.9157 & -1.9957 & -1.5007 \\
Azerbaycan & $-9.454^{* * *}$ & -3.1442 & -2.2785 & -1.8107 \\
Kazakistan & $-9.750^{* * *}$ & -2.9612 & -2.0607 & -1.5745 \\
Özbekistan & $-10.068^{* * *}$ & -2.5608 & -1.6838 & -1.1981 \\
Tacikistan & $-10.454^{* * *}$ & -2.6488 & -1.9100 & -1.5344 \\
Türkmenistan & $-3.232^{* * *}$ & -3.0857 & -2.3400 & -1.9252 \\
\hline
\end{tabular}

Not: *** \%1 düzeyinde anlamlılı̆̆ ifade etmektedir. Kritik değerler 10.000 Bootstrap ile elde edilmiştir.

Elde edilen doğrusal olmayan SURKSS birim kök test sonuçlarına göre test istatistiklerinin kritik değerlerden küçük olduğu ve sıfır hipotezinin reddedildiği görülmektedir. Dolayısıyla her bir ülkenin durağan bir yap1 sergilediği sonucuna varılmaktadır. Dş borç Türki Cumhuriyeti ülkeleri için sürdürülebilirlik özelliği taşıdığı sonucuna varılmaktadır. Analize konu olan ülkelerde dış borç servislerinin sürdürülebilirliğini gösteren bu sonuçlar, özellikle Türkiye için daha önce yapılmış çalışmalar ile karşılaştırıldığında literatür ile ters düşmektedir. Bu durum uygulanan birim kök testinin mevcut çalışmalarda kullanılan birim kök testleri farklıllğından ileri gelebilir. Nasir ve Noman (2012) ve Sawada (1994) çalışmalarında ortaya çıkan gelişmekte olan ülkelerin yetersiz tasarruf birikimi nedeniyle yatırımları finanse etmede dış kaynak kullanımına yöneldikleri önerisi bu çalışmada geçerli olmamaktadır. Ülkelere 
genel olarak bakıldığında, özellikle doğal kaynak ve hammadde açısından zengin olmaları dış borcun çevrilebilirliği problemini ortadan kaldırdığı söylenebilir.

\section{Tartışma, Sonuç ve Öneriler}

1990'lardaki döviz krizleri ve uluslararası borç dalgası, bir ülkenin ekonomik büyümesini sürdürmek için dış yardımların ne kadar sürdürülebilir olduğu sorusunu gündeme getirmiştir. Dış borçların, bir ülke mevcut ve gelecekteki dış borç servisi yükümlülüklerini tam olarak karşılayabildiğinde sürdürülebilir olduğu ifade edilmektedir. Diğer bir deyişle, sürdürülebilirlik, borçlunun geri ödeme kapasitesi ile uyumlu olmasını gerektirecektir. Bir ülkenin çok yüksek düzeyde borç oranlarıyla karşı karşıya olduğu durumda, borç ödemesi sadece ekonomik performansı kısıtlamakla kalmaz, elde edilmesi neredeyse imkânsız olabilir. Sürdürülebilirlik araştırmalarında, dış borcun durağanlığı, zamanlar arası bütçe kısıtlamasının geçerliliği için esastır. Birim kök ve eşbütünleşme testleri, bir hükümetin veya ülkenin zamanlar arası ödeme gücünün uygulanması için yararlı araçlar sağlamaktadır. Bu testler, bir hükümetin veya ülkenin borcunu ödemeksizin bütçesini veya dış açıklarını devam ettirip ettiremeyeceğini belirlemeye olanak sağlamaktadır. Bu sayede mali politikalara yön verilebilmekte ve ekonomik ve sosyal adımlar için kararlar alınmaktadır. Bunun haricinde ülkelerde finansal istikrarın sağlanmasına da katkıda bulunmaktadır. Aksi şekilde yüksek hacimli dış borç yükü, devlet açığının yan ürünüdür ve ülkenin ödeme gücü riskini arttırmaktadır.

Bu çalışmada seçilen ülke grubu için dıș borcun sürdürülebilir olup olmadığının belirlenmesi için uygulanan yatay kesit bağımlllk testi neticesinde ikinci kuşak testlerden olan ve doğrusal olmayan panel birim kök analizi yapılmıştır. Analizi gerçekleştirilecek veri seti dış borç stokunun büyüme verilerine oranlaması ile elde edilmiştir. 1996-2019 dönemlerini kapsayan veri seti için yapılan sınamada düzeyde durağan çıktığ1 yani $\mathrm{I}(0)$ olduğu görülmektedir. Yani seçilen Türki Cumhuriyet ülkeleri için dış borcun ölçüleri doğrusal olmayan sürdürülebilir olduğu sonucuna varılmıştır.

Arize (2002), doğrusal teknikler kullanarak Portekiz, Guatemala ve Paraguay'ın borç ölçülerini sürdürülemez olarak ifade etmiştir. Fakat bununla birlikte, Nasir ve Noman (2012) doğrusal olmayan çerçevede yaptıkları çalışmada üç ülkenin de borç ölçülerini hem doğrusal olmayan hem de sürdürülebilir olduğunu bulmuşlardır ve yanlış çıkarıma dayalı yanlış politika önerilerinin, istenmeyen sonuçları tetikleyebileceklerinden bahsetmişlerdir. Bu çalısmada hem doğrusal (SURADF) hem de doğrusal olmayan (SURKSS) birim kök sonuçları raporlanmıştır. Doğrusal SURADF birim kök test sonuçlarına göre sadece Tacikistan'ın \%10 seviyesinde dış borcun sürdürülebilir olduğu, diğer ülkelerin ise dış borcunun sürdürülemez olduğu bulgusuna ulaşılmıştır. SURKSS birim kök testi sonucuna göre ise seçilen ülke grubu için doğrusal olmayan çerçevede dış borcun sürdürülebilir olduğu bulgusuna ulaşılmıştır.

Borçlarının daha uzun bir süre büyümesine izin veren ekonomiler, borç hedefleme eşiğini aşma tehlikesiyle karşı karşıyadır. Bu, özellikle kamu harcamaları, vergilendirme ve borçlanma konusunda geniş kapsamlı kararlar veren gelişmekte olan ülkeler için geçerlidir. Bir ülkenin, ulusal ekonomi gündeminin önemli bir parçası olacak uzun vadeli büyüme beklentilerini tehlikeye atmadan ne kadar borç alabileceğini belirlemesi önemlidir. Kapalı ekonomide iç borç, ekonominin finansmanı için tek seçenekti, ancak açı ekonomide ülkeler ve ekonomik yapıları birbirine bağlı olduğundan, dış borç, serbestleşmeyle iç borcu ikame etmektedir. Ülkenin borç servis ihtiyacını karşılama ve borç çevirme riskini azaltma ihtiyacını karşılayan dış borç, iç borçlanmaya göre daha uzun vadeli, kullanışlı bir borçlanma aracıdır. Dış borç, yararlı bir finansman aracı olmasına rağmen, güvenilirlik kaygıları nedeniyle dış borcun gecikmeden geri ödenmesine özen gösterilmelidir.

\section{Etik Beyan}

"Türki Cumburiyetlerinde Dıș Borç Sürdürülebilirlike Analizi: Doğrusal Olmayan Panel Birim Kök Testi” başliklı çalışmanın yazım sürecinde bilimsel kurallara, etik ve alıntı kurallarına uyulmuş; toplanan veriler üzerinde herhangi bir tahrifat yapılmamış ve bu çalışma herhangi başka bir akademik yayın ortamına değerlendirme için gönderilmemiştir. Bu araştırmada hazır veri seti kullanıldığ için etik kurul kararı zorunluluğu taşımamaktadır.

\section{Kaynakça}

Arize, A.C. (2002). Test of cointegration and structural breaks. International Review of Economics and Finance, 11, 101-15. doi:10.1016/S1059-0560(01)00101-0 
Boengiu, T., Triandafil, C. M., ve Triandafil, A. M. (2011). Debt ceiling and external debt sustainability in Romania: a quantile autoregression model. Romanian Journal of Economic Forecasting, 4, 15-29. Erişim adresi: http://www.rjef.ro/rjef/rjef4_11/rjef4_2011p15-29.pdf

Breuer, J. B., McNown, R. ve Wallace, M. S. (2001). Misleading Inferences from Panel Unit-Root Tests with an Illustration from Purchasing Power Parity. Review of International Economics, 9(3), 482-493. doi: 10.1111/14679396.00294

Breuer, J. B., McNown, R. ve Wallace, M. (2002). Series-Specific Unit Root Tests with Panel Data. Oxford Bulletin of Economics and statistics, 64(5), 527-546. doi:10.1111/j.1467-9396.2006.00588.x

Buiter, W. H. ve Patel, U. R. (1992). Debt, deficits, and inflation: an application to the public finances of India. Journal of public Economics, 47(2), 171-205. Erişim https://www.nber.org/system/files/working papers/w3287/w3287.pdf

Caporale, G. M. (1995). Bubble finance and debt sustainability: a test of the government's intertemporal budget constraint. Applied Economics, 27(12), 1135-1143. doi:10.1080/00036849500000096

Croce, E. ve Juan-Ramon, V. H. (2003). Assessing Fiscal Sustainability: A Cross- Country Comparision, IMF Working Paper WP/03/145.

Çakmak, U. (2020). Türkiye'de Diş Borçların Sürdürülebilirliği ve Ekonominin Finansal Kırılganlığı Üzerine Analizler: 1989-2019, Üçücü Sektör Sosyal Ekonomi Dergisi, 55(3), 1837-1862

Göktan A. (2008). Türkiye'de Mali Sürdürülebilirlik Üzerine Ampirik Bir Çalışma. Marmara Üniversitesi İIBF Dergisi, 15(2).

Göktaş, Ö. ve Hepsağ, A. (2015). The analysis of external debt sustainability by periodic unit root test with structural break: The case of Turkey. Research in Applied Economics, 7(4), 1-15. doi:10.5296/rae.v7i4.8123

Hamilton, J.D., ve Flavin, M.A. (1986), On the Limitations of Government Borrowing: A Hamework for Empirical Testing. American Economic Review, 76(4), 808-819. Erişim adresi: https://citeseerx.ist.psu.edu/viewdoc/download?doi=10.1.1.416.2165\&rep=rep1\&type $=$ pdf

Hauner, D., Leigh, D. ve Kumar, S. M. (2007). Ensuring Fiscal Sustainability in G-7 Countries, IMF Working Paper WP $/ 07 / 187$.

Hepsağ, A. (2011). Mali Politikaların Sürdürülebilirliğinin Yapısal Kırılmalı Periyodik Birim Kök Testi ile Analizi: Türkiye Örneği, Doğus Üniversitesi Dergisi, 12(1), 32-45.

International Monetary Fund. (2002). Assessing sustainability. Policy Department and Review Department. Washington, USA.

Kapetanios G., Shin Y. ve Snell A. (2003). Testing for a Unit Root in the Nonlinear STAR Framework. Journal of Econometrics, 112, 359-379. Doi: 10.1016/S0304-4076(02)00202-6

Kıran, B. (2012). The sustainability of Turkish external debt: evidence from fractionally integrated approach under structural breaks. Economic research-Ekonomska istraživanja, 25(1), 18-29. Erişim adresi: https://doi.org/10.1080/1331677X.2012.11517491

Lau, E. ve Baharumshah, A. Z. (2005). Mean-reverting behavior of current account in Asian countries. Economics Letters, 87(3), 367-371. Erişim adresi: https://doi.org/10.1016/j.econlet.2005.01.006

Lau, E., Baharumshah, A. Z. ve Soon, S. V. (2013). The behavior of external debt in Asian countries: evidence based on panel unit root tests. Journal of Business Economics and Management, 14(sup1), S377-S394. Erişim adresi: https://doi.org/10.3846/16111699.2012.720589

Lin, M. Y. (2014). The Sustainability of External Debt in OECD Countries: Evidence from Quantile Autoregression. Research in World Economy, 5(2), 31-42. doi:10.5430/rwe.v5n2p31

Mendoza, E. G. ve Ovied, P. M. (2004). Fiscal Solvency and Macroeconomic Uncertainty in Emerging Markets: The Tale of the Tormented Insure, NBER Working Paper.

Mohammadi, H., Cak, M. ve Cak, D. (2007). Capital mobility and foreign debt sustainabilty: some evidence from Turkey. Applied Economics, 39(19), 2441-2449. doi: 10.1080/00036840600707274

Nasir, A. ve Noman, A. M. (2012). Sustainability of external debt: further evidence from non-linear framework. International Review of Applied Economics, 26(5), 673-685. doi: 10.1080/02692171.2012.665853

Ono, H. (2008). Searching for Non-Linear Effects and Fiscal Sustainability in G-7Countries, Applied Economics Letters, (15), 457-460.

Önel, G. ve Utkulu, U. (2006). Modeling the long-run sustainability of Turkish external debt with structural changes. Economic Modelling, 23(4), 669-682. Erişim adresi: https://doi.org/10.1016/j.econmod.2006.03.006

Polat, M. A. ve Fendoğlu, E. (2021). Etkin Ücret Teorisi Çerçevesinde Türkiye'de Reel Ücretler İle Üretim Arasındaki İlişkinin İncelenmesi: Sektörler İle Ekonometrik Bir Analiz. Yönetim ve Ekonomi Araştırmalar Dergisi, 19(1), 331-348.

Pradelli, J. J. (2006), “On External Debt Sustainability and the Argentine Crisis", Erişim adresi: http://193.205.83.2/ confeco/papers/pradelli.pdf

Sawada, Y. (1994). Are the heavily indebted countries solvent?: Tests of intertemporal borrowing constraints. Journal of Development Economics, 45(2), 325-337. Erişim adresi: https://doi.org/10.1016/0304-3878(94)90036-1

Takeuchi, F. (2010). US external debt sustainability revisited: Bayesian analysis of extended Markov switching unit root test. Japan and the World Economy, 22(2), 98-106. doi: 10.1016/j.japwor.2009.12.001 
Trehan, B., ve Walsh, C. (1988). Common trends, the government's budget constraint, and revenue smoothing. Journal of Economic Dynamics and Control, 12 (2-3), 425-444. Erişim adresi: https://doi.org/10.1016/0165$\underline{1889(88) 90048-6}$

Trehan, B. ve Walsh, C. (1991). Testing intertemporal budget constraints: Theory and applications to U.S. federal budget and current account deficits. Journal of Money, Credit and Banking, 23 (2), 206-223. Erişim adresi: https://www.jstor.org/stable/pdf/1992777.pdf?refreqid=excelsior\%33A74b569d951d80c860280f35c1c9c1f81

Ucal, M. ve Alici, A. (2010). Is Fiscal Policy Sustainable in Turkey, Emerging Markets Finance and Trade, 46(1), 83-93.

Wu, J. L. (2000). Mean reversion of the current account: evidence from the panel data unit-root test. Economics Letters, 66(2), 215-222. Erişim adresi: https://doi.org/10.1016/S0165-1765(99)00198-6

Wu, J. L. ve Lee, H. Y. (2009). A Revisit to the Non-Linear Mean Reversion of Real Exchange Rates: Evidence From A Series-Specific Non-Linear Panel Unit-Root Test, Journal of Macroeconomics, 31 (2009) 591-601. doi: 10.1016/j.jmacro.2008.12.002

Yalçınkaya, Ö. (2019). Türkiye Ekonomisinde Dış Borçların Sürdürülebilirliğinin Analizi: Doğrusal ve Doğrusal Olmayan Birim Kök Testlerinden Kanıtlar (1970-2018). Maliye Dergisi, 176, 27-51. Erişim adresi: https://ms.hmb.gov.tr/uploads/2019/09/176-02.pdf

Yilanc1, V. ve Özcan, B. (2008). External debt sustainability of Turkey: A nonlinear approach. International Research Journal of Finance and Economics, 20(10), 91-99. Erişim adresi: https://www.researchgate.net/publication/200444383 External Debt Sustainability of Turkey_A Nonlinear Approach

\section{EXTENDED ABSTRACT}

The role of external debt sustainability is extremely important in terms of fiscal policies. Therefore, the foreign debt burden of countries is seen as one of the most important obstacles to economic and social progress. Therefore, external debt sustainability is one of the key elements in analyzing the financial stability of a country's economy. Sustainability is considered one of the most important research areas, especially for developing countries. Large external debt accumulation is a byproduct of the state deficit. Higher external debt increases the country's solvency risk. Many studies are being developed on debt reduction strategies as a strategy to deal with this situation. There are some difficulties in defining sustainability and it is stated that there is no consensus among economists on the terms of sustainability. Many definitions are used for external debt sustainability. In summary, sustainability is the situation where the present value of a country's net future net foreign income is equal to the present value of its foreign debt. Increasing foreign debt stock in the economies of the country causes a decrease in production and export revenues. Apart from this, it increases the risk premium and causes a decrease in capital input and an increase in output. In addition, as they lower the credit ratings of the countries, the tax demands of the states increase and therefore the investments decrease.

The sustainability of foreign debt on behalf of countries is extremely important fiscal and financially. For this purpose, this subject has been the focus of attention by many researchers. This issue has become even more important since 1996, as debt deferral initiatives for some low-income countries are for the first time based in part on the goal of making the countries' debt sustainable, rather than the lowest common denominator desired by creditors (Kiran, 2012: s. 18). The preferred options to test the sustainability issue are unit root (stationarity) and cointegration tests. In the literature, there are many studies conducted for various country or country groups for the external debt sustainability test. However, the results differ according to the econometric methods used.

In this study, it has been investigated whether foreign debt is sustainable for the economies of Turkey, Kyrgyzstan, Azerbaijan, Kazakhstan, Uzbekistan, Tajikistan and Turkmenistan, which are included in the Turkic Republics, with annual data covering the period 1996-2019. Observations have been obtained from the World Bank official database. Whether the foreign debt exhibits a sustainable structure for the selected country group has been determined by nonlinear panel unit root analysis. Crosssection dependency analysis was performed on the series before, and since the series were found to be cross-sectionally dependent, second generation unit root test was applied.

The biggest advantage of choosing panel unit-root tests is that its power can be increased by using cross-sectional information. Among the available methods, all studies in the literature adhere to a linear structure to test the combined unit root hypothesis under well-known constraints that rejecting the null hypothesis provides little information for the stationarity of individual series. This test, proposed by Wu and Lee (2009), proposed a model structure based on the assumption that the series follows a nonlinear structure with the Seemingly Unrelated Regression (SUR) equations. In this model, the series-specific 
nonlinear panel unit root test is used to analyze the nonlinear mean of the series. The data generation process has been set up to reflect important nonlinear behavior. Nonlinear series-specific panel unit root test Breuer et al. (2001) showed that it is stronger than the SURADF test. In this test, the nonlinear regression pattern proposed by Kapetanios et al. (2003, KSS) is used instead of the ADF regressions used in the SURADF panel unit root test. It also uses cross-sectional information in series and takes into account simultaneous correlation and heterogeneous serial correlation.

According to the nonlinear unit root test results obtained, it is seen that the test statistics are less than the critical values and the null hypothesis is rejected. Therefore, it is concluded that each country exhibits a stationary structure. In other words, it is concluded that the foreign debt has a sustainability feature for the countries of the Turkic Republic. In a closed economy, domestic debt was the only option for financing the economy, but since countries and their economic structures are interdependent in an open economy, external debt substitute's domestic debt with liberalization. Meeting the country's need for debt service and reducing the risk of debt rollover, external debt is a longer term and useful debt instrument than domestic borrowing. Although external debt is a useful financing tool, attention should be paid to repaying external debt promptly due to reliability concerns. 